\title{
Identifying Common Practices and Challenges for Local Urban Tree Monitoring Programs Across the United States
}

\author{
Lara A. Roman, E. Gregory McPherson, Bryant C. Scharenbroch, Julia Bartens
}

\begin{abstract}
Urban forest monitoring data are essential to assess the impacts of tree planting campaigns and management programs. Local practitioners have monitoring projects that have not been well documented in the urban forestry literature. To learn more about practitioner-driven monitoring efforts, the authors surveyed 32 local urban forestry organizations across the United States about the goals, challenges, methods, and uses of their monitoring programs, using an e-mailed questionnaire. Non-profit organizations, municipal agencies, state agencies, and utilities participated. Onehalf of the organizations had six or fewer urban forestry staff. Common goals for monitoring included evaluating the success of tree planting and management, taking a proactive approach towards tree care, and engaging communities. The most commonly recorded data were species, condition rating, mortality status, and diameter at breast height. Challenges included limited staff and funding, difficulties with data management and technology, and field crew training. Programs used monitoring results to inform tree planting and maintenance practices, provide feedback to individuals responsible for tree care, and manage tree risk. Participants emphasized the importance of planning ahead: carefully considering what data to collect, setting clear goals, developing an appropriate database, and planning for funding and staff time. To improve the quality and consistency of monitoring data across cities, researchers can develop standardized protocols and be responsive to practitioner needs and organizational capacities.

Key Words. Citizen Science; Forest Inventory and Analysis; i-Tree; Monitoring; Survey; Tree Mortality; Tree Planting.
\end{abstract}

The proliferation of urban forest inventory systems in the past few decades has allowed practitioners and researchers to quantify forest structure and function, estimate ecosystem services, and manage tree maintenance issues (Miller 1996; McPherson et al. 1999; Nowak and Crane 2000; Brack 2006; Keller and Konijnendijk 2012). Standardized inventory systems have enabled comparisons of tree density, species composition, and cost-benefit ratios across cities (McPherson and Simpson 2002; McPherson et al. 2005; Nowak et al. 2008). While these inventories have enhanced researchers' understanding of urban forests, they provide a snapshot in time, and can quickly become outdated in a changing, complex urban landscape. Long-term monitoring data are essential to understand change over time in urban forests-including trends in tree mortality, growth, longevity, and health—and to assess the impacts of tree planting campaigns and management programs.

Although urban forest researchers and arborists have long recognized the value of monitoring data and systematically updated inventories (Weinstein 1983; Baker 1993; McPherson 1993; Clark et al. 1997; Dwyer et al. 2002, Rysin et al. 2004), they do not yet have coordinated programs to conduct longitudinal studies. The need for long-term monitoring was raised at a recent conference on urban tree growth and longevity (Leibowitz 2012). There have been several long-term monitoring programs in wildland (i.e., non-urban) forest ecosystems in the United States, including the Forest Inventory and Analysis (FIA) and Forest Health Monitoring programs of the United States Department of Agriculture (USDA) Forest Service and Long-Term Ecological Research (LTER) sites sponsored by the National Science Foundation. Although these monitoring programs focus primarily on non- urban systems, the methods and analytical tools can be adapted to urban systems. This is already happening with FIA urban pilot programs (Cumming et al. 2008). The Forest Service has also collected repeated plot-based data using i-Tree Eco in Baltimore, Maryland and Syracuse, New York, U.S. (Nowak et al. 2004; D.J. Nowak 2013. Additionally, there are two LTER sites in urban environments: Baltimore, Maryland and Phoenix, Arizona, U.S.

While researchers pursue long-term data collection in cities, local urban forest practitioners are also engaged in monitoring. Two examples have been published online (Boyce 2010; Lu et al. 2010), but other local monitoring programs exist that are not well documented in the literature. Local monitoring programs are important because cities and their non-profit partners are directly involved with the planting and management of many trees in U.S. cities. By monitoring the trees they plant and maintain, these local programs can adjust their management practices based on performance that is quantified, not anecdotal. Standardized protocols for urban tree monitoring would underpin comparative analyses for benchmarking performance among programs and across time, and promote data sharing among professionals and researchers (Leibowitz 2012).

To assist in the development of standardized urban forest monitoring protocols, the authors sought to learn more about the goals and operations of practitioner-driven monitoring. A questionnaire was disseminated to urban forestry organizations across the United States, specifically targeting local organizations that already conduct monitoring programs and generate longitudinal data. The survey assessed: 1) common goals and motivations for monitoring; 2) the range of meth- 
ods employed; 3) common challenges; and 4) uses of monitoring data. Participants were also asked to offer suggestions for other local organizations seeking to collect monitoring data, and for researchers aiming to develop standardized protocols.

\section{METHODS}

\section{Study Design and Participant Recruitment}

The authors targeted local urban forestry organizations in the United States that have collected urban tree monitoring data; only organizations with longitudinal data on individual trees were relevant to the research. Throughout this paper, the term "monitoring" is used to refer to systematically collected data on the same trees over time, and "inventory" in reference to a one-time snapshot of urban forest characteristics. Organizations with lists of planted trees lacking static inventories, follow-up records, or sporadically updated inventories were not included in this study.

To understand practitioner-driven monitoring efforts, the study authors specifically sought monitoring programs developed and led by local urban forestry organizations, rather than researcherdriven monitoring studies (e.g., Nowak et al. 2004; Cumming et al. 2008). Eligible organizations were identified through researcher and peer recommendations. The authors began with a list of a dozen organizations that were known to have relevant monitoring programs. Next, a snowball or chain referral sampling technique was used, asking for peer recommendations from colleagues and staff at the local organizations already identified. Sixty-seven organizations were identified through this process.

Participants were recruited via e-mail in February-April 2012, followed by a phone call to explain the study purpose and verify whether the organization had relevant urban tree monitoring programs. Seventeen organizations did not have relevant monitoring programs, 16 were unresponsive to recruiting attempts, and 34 agreed to participate in the study. Questionnaires were emailed to staff at each of the 34 recruited organizations, with several reminder e-mails and phone calls as needed. Questionnaire design and recruitment techniques were adapted from Dillman's Tailored Design Method (Dillman 1999). Thirtytwo organizations completed the survey-a $94 \%$ participation rate of those recruited. Most participants completed the survey via e-mail, but one dictated responses over the phone.

\section{Survey Format}

The survey contained organization-level and program-level questions. Some organizations had more than one distinct monitoring program; in these situations, the program-level questions were repeated. For example, a few organizations conducted both a cohort mortality study of recently planted trees and a repeated census of neighborhoods or plots. Surveys were customized to each organization with the name(s) of their program(s). Fortyfive distinct monitoring programs were included from the 32 participating organizations. Organization-level questions inquired as to the type of organization, number of paid urban forestry staff, challenges with urban tree monitoring, experiences sharing monitoring methods and results, and recommendations for other local organizations and researchers undertaking monitoring projects. The number of full-time equivalent paid staff was limited to individuals working on urban forestry and urban greening issues. This enabled more meaningful comparison of staff at different organizations (e.g., municipalities reported the number of urban forestry employees in the parks and/ or streets division, rather than the total staff across all departments). Program-level questions included motivations for the specific monitoring program(s), processes of developing field methods, types of data collected, and uses of monitoring data.

The survey included both multiple-choice and open-ended questions. Multiple-choice questions were usually presented as "check all that apply," including an option for "other," to account for categories that were not anticipated. Responses were re-coded in the "other" category to fit the original categories whenever possible (i.e., it is determined that the participant's explanation for the "other" response fit a category already listed). In a few cases, several participants gave similar responses for the "other" explanation, and the study authors created new response categories.

\section{Data Analysis}

Open-ended questions were qualitatively assessed for common themes, counting the number of times participants mentioned similar ideas (Babbie 2007). Themes were not pre-determined. The open-ended questions were independently analyzed by one of the authors and a research assistant, with later discussion to resolve discrepancies in the interpretations. Differences in interpretation typically related to lumping versus splitting topics. Direct quotations from participants are included to provide a deeper view of their experiences and perspectives. Quotes are presented anonymously, with spelling errors corrected.

Results are presented for both the open-ended and multiple-choice questions as a percent of the total number of organization-level or program-level responses. In a few cases, responses were left blank, and in those situations the authors divided by the total number of actual responses for that particular question. For both multiple-choice and openended questions, percentage totals are typically $>100 \%$, because respondents were not forced to choose only one option.

\section{RESULTS}

\section{Types of Organizations Represented}

Participating organizations $(n=32)$ are mainly non-profits $(53 \%)$ and municipalities $(38 \%)$, with a smaller proportion of state governments $(9 \%)$ and utilities $(6 \%)$. These organizations are located in 17 states plus Washington, D.C. (see Roman 2013 for a complete list of organizations). Most non-profit organizations are focused on urban forestry and urban greening; two are neighborhood associations. The organizations serve a range of geographic areas: cities/municipalities (72\%), counties $(31 \%)$, regions $(25 \%)$, neighborhoods $(22 \%)$, and states $(6 \%)$. The number of full-time equivalent urban forestry staff of these organizations also varies widely $(\min =0,25$ th percentile $=3$, median $=6,75$ th percentile $=22, \max =174$ ) .

\section{Goals and Motivations for Monitoring}

The most common goals (51\%) for urban tree monitoring programs were to track tree survival, health, and/or growth, and measure program success. 'Success' itself was generally not clearly defined by respondents, but tree survival and health were implied. Some programs also aimed to evaluate factors 
related to survival, such as species, planting stock, and maintenance. One participant explained the program goals as follows:

[Our organization] had an assumed survival rate when I started, but nothing to back it up. I wanted to have a legit number that we can claim as the success of our planting and care work.

Another common motivation was conducting monitoring as a proactive approach toward tree care, maintenance, and management (44\%). Monitoring data collection was sometimes done at the same time as, or in preparation for, tree maintenance work. Twenty-one percent of program-mostly at non-profit organizations - conducted tree monitoring to educate and engage volunteers, residents, and communities.

Tree monitoring programs were sometimes required by grants or contract obligations; $16 \%$ of programs mentioned this as part of their motivation for conducting monitoring. Of all programs, $51 \%$ had external funding, and of those with funding, monitoring was required for $48 \%$.

\section{Monitoring Methods}

Programs developed their field methods for urban forest monitoring using a mix of in-house program staff (46\%) and external assistance (17\%). Participants worked with paid consultants, university or USDA Forest Service researchers, and other local urban forestry organizations. Some programs $(12 \%)$ adapted their monitoring methods from the i-Tree inventory software (www. itreetools.org), which was developed by the Forest Service. Field work was carried out mostly by program staff $(62 \%)$, followed by volunteers $(42 \%)$, arborists $(36 \%)$, researchers $(16 \%)$, interns $(16 \%)$, and contractors $(4 \%)$. Thirty-three percent of programs developed a field manual for their monitoring project.

The most commonly recorded tree characteristics for urban tree monitoring programs were species $(96 \%)$, condition rating $(89 \%)$, mortality status $(76 \%)$, diameter at breast height (DBH; 71\%), and specific health problems (67\%). Many other tree size metrics, maintenance issues, and site characteristics were recorded (Table 1). Half (53\%) of the programs exclusively monitor trees planted by their organization, while others monitor only trees not planted by their organization $(9 \%)$ or both $(38 \%)$. Street trees were the most common $(86 \%)$ type of tree location included in these programs, followed by public park trees (45\%), institutional trees (34\%), residential yard trees $(25 \%)$, conservation areas $(7 \%)$, and other $(14 \%)$. The most common way to record tree location was street address (78\%), with many other techniques employed (Table 2); tree location was often recorded in several ways.

The sampling designs for these monitoring programs also varied widely. Seventy-three percent used a complete survey of all trees in a particular program or neighborhood, $16 \%$ used a stratified random sample, $9 \%$ used a simple random sample, $7 \%$ used a convenience sample (i.e., trees or plots selected based on convenience for program personnel), $7 \%$ used a targeted sample (i.e., trees chosen based on program interests, such as limiting to a few species), and $4 \%$ used another sampling technique. In terms of observation intervals, $64 \%$ of programs used a fixed time interval, $43 \%$ used a one-time monitoring of recently planted trees, $18 \%$ used a rolling schedule (e.g., visit $20 \%$ of all trees every year, to reach all trees in five years), and $30 \%$ used another observation interval. Some of these monitoring programs were very recently implemented $(43 \%$ of programs had been instituted within 1-5 years of the survey), while other programs were well established within the organization $(26 \%$ for $6-10$ years, $14 \%$ for $11-20$ years, and $17 \%$ for $>20$ years).

Monitoring data were managed using a wide assortment of software, including Excel (49\%), Access (44\%), GIS (22\%), i-Tree (18\%), Lucity (7\%), TreeKeeper (4\%), and other $(20 \%)$. Thirty-seven percent of programs have a paid staffer dedicated to the management of tree monitoring databases.

Table 1. Field data included by practitioner-based urban tree monitoring programs $(n=45)$.

\begin{tabular}{ll}
\hline Data collected & Percent of total \\
\hline Tree characteristics & \\
Species & $96 \%$ \\
Health condition rating & $89 \%$ \\
Mortality status & $76 \%$ \\
Diameter at breast height & $71 \%$ \\
Specific health problems & $67 \%$ \\
Height & $38 \%$ \\
Canopy width & $31 \%$ \\
Canopy dieback & $27 \%$ \\
& \\
Maintenance issues & \\
Pruning & $56 \%$ \\
Watering & $47 \%$ \\
Mulching & $47 \%$ \\
Infrastructure conflicts & $42 \%$ \\
Staking & $36 \%$ \\
Other tree care issues & $9 \%$ \\
& \\
Site characteristics & \\
Location type & $47 \%$ \\
Land use & $36 \%$ \\
Ground cover & $27 \%$ \\
Soil characteristics & $13 \%$ \\
Canopy cover & $4 \%$ \\
Other site characteristics & $13 \%$ \\
Other & $13 \%$ \\
\hline
\end{tabular}

Table 2. Methods of recording tree location in monitoring programs $(n=45)$

\begin{tabular}{ll}
\hline Method & Percent of total \\
\hline Street address & $78 \%$ \\
GPS & $42 \%$ \\
Site maps & $31 \%$ \\
Tree tags & $16 \%$ \\
Google maps & $13 \%$ \\
Reference point & $11 \%$ \\
Map cell number & $4 \%$ \\
Other & $18 \%$ \\
\hline
\end{tabular}

\section{Challenges with Monitoring}

Resource limitation (63\%) was the most common challenge to urban tree monitoring at these organizations. Specifically, 50\% mentioned lack of staff time and $25 \%$ mentioned lack of dedicated funding. Data management and technology challenges were also common $(47 \%)$, such as time-intensive data entry and management, identifying appropriate software for long-term tree records, and adapting other technologies for tree monitoring. Twenty-eight percent of organizations had challenges developing protocols, including deciding what data to collect, subjectivity of tree condition ratings, and instituting quality assurance and quality 
control. Twenty-five percent had difficulties with field crew recruitment and/or training, especially for volunteers and student interns. Twenty-five percent had problems implementing the field work, such as reliably locating tree and plots and getting access to private properties. One participant summarized many of the common challenges as follows:

Not knowing what to monitor, no one to monitor, not knowing what questions to ask of the monitoring.

Organizations had many solutions to these challenges. Twentyfive percent improved the process of recruiting and training field crews, particularly non-profit organizations relying on volunteers and student interns. For example, some organizations decided to hire only college-level interns, while others added more training days. Twenty-five percent had solutions to address funding problems. These tactics included incorporating monitoring and staff time into organizational budgets, seeking external grants, and using volunteers. Thirteen percent prioritized data collection to meet immediate management needs, such as tree risk issues for municipal agencies. Other solutions were staff and volunteer dedication $(9 \%)$ and advice from external consultants or peers $(9 \%)$. Twenty-two percent of organizations noted that challenges remain and have not been solved.

\section{Uses of Local Monitoring Data}

Participants were asked whether monitoring programs influence management at their organizations; $78 \%$ said yes. Of these, $60 \%$ said that monitoring informs tree planting techniques and maintenance practices. Forty-three percent said that monitoring affects tree species selection, helping to maximize diversity and selection of appropriate species. Twenty-three percent used monitoring to provide feedback to individuals responsible for tree care, such as residents, volunteers, contractors, and municipalities. Twenty percent used monitoring data for tree risk management, often connected to liability and disease concerns; this issue was most commonly mentioned by municipalities.

Data analysis at these programs involved summary statistics $(81 \%)$, overall survival and/or growth rates $(69 \%)$, comparisons of survival and growth across groups (50\%), spatial analysis $(31 \%)$, statistical analysis such as $\chi^{2}$ and ANOVA $(19 \%)$, and other techniques $(17 \%)$. Data analysis was carried out by program staff $(83 \%)$, interns $(8 \%)$, researchers $(8 \%)$, volunteers (8\%), and consultants (3\%). Sixty percent of programs produced written reports on their monitoring projects; two of these were published (Boyce 2010; Lu et al. 2010).

\section{Sharing Monitoring Methods and Results}

Participants were asked whether their organizations shared information about their tree monitoring program(s) with other urban forestry organizations; $56 \%$ said yes. Information was shared through a variety of mechanisms. Fifty-six percent of those who share information did so through direct communication with colleagues at other organizations, 33\% shared through state or regional networks, and $22 \%$ shared at conferences.

Participants described the value in sharing monitoring methods and results across cities. Fifty-five percent valued the opportunity to learn from the best practices and methods in other cities and programs. Twenty-one percent commented that sharing methods and approaches can lead to greater efficiency:
It increases efficiency-you don't have to "re-create the wheel" for each tree planting/monitoring program. We can learn from other's experience.

Organizations also valued the ability to share findings across cities and programs (21\%), with some specifically noting the value of standardized methods for meaningful comparison of data (17\%).

\section{Suggestions for Other Practitioners and Researchers}

Participants were asked to offer guidance to another local urban forestry organization seeking to develop a tree monitoring program. Most recommendations addressed the importance of advance planning. Fifty-two percent of respondents emphasized the importance of thinking carefully about methods and data collection. Forty-two percent said that monitoring programs should have clear goals and intended uses of the data. Forty-two percent mentioned the importance of a good database, especially of the initial inventory or planting records. Twenty-nine percent suggested planning ahead for budgeting, funding, staffing needs, and field crew time. One participant captured many of these common recommendations as follows:

They need to know what the purpose is for the information. If you're taking the time to do it, what's the point? This helps drive what data you collect. Know who is going to do the work, and make sure they have the time and experience to do it properly.

Participants were also asked how researchers can be useful to enhance their urban forest monitoring program(s). Forty-four percent asked researchers to provide best practices and methods for monitoring, including standardized protocols. For example, one participant noted that small organizations have limited capacity, and would appreciate input from researchers on best practices for tree monitoring.

Twenty-two percent of organizations suggested that researchers should develop tools for monitoring, such as technology and software solutions. Nineteen percent requested that researchers continue to produce information on tree benefits and ecosystem services, which help justify funding for urban forest programs. Fifteen percent would like researchers to provide accurate estimates of tree mortality, growth, and canopy change. Eleven percent noted that university and/or government researchers have already been useful.

Finally, the study authors asked for recommendations with the development of standardized urban tree monitoring protocols. Thirty-one percent suggested that protocols should be adaptable to different organizational capacities and needs, and be flexible for different situations. Another suggestion (21\%) was to be inclusive and involve practitioners in the protocol development process. Some participants $(21 \%)$ stressed the importance of keeping protocols simple for users, rather than "complicated and academic."

\section{DISCUSSION}

Common goals and motivations for practitioner-driven urban forest monitoring emerged from the analysis. These goals were often echoed in later responses about field methods and uses of the data. For example, programs that evaluated trees planted by their organization used the re- 
sults to inform planting practices, and municipalities that managed mature urban trees tracked potential hazard trees, and used the results to prioritize maintenance. However, not all programs had clear linkages between monitoring goals, field methods, and uses of the data. At the same time, when asked to offer guidance for other organizations embarking on tree monitoring programs, participants' most common recommendations were to carefully consider what data to collect and have clearly articulated goals.

Research ecologists have similarly stressed the importance of clear questions and objectives in long-term monitoring (Lindenmayer and Likens 2010). Monitoring is not a goal in and of itself, but rather, a means to answering questions (Lovett et al. 2007; Lindenmayer and Likens 2010). Other attributes of effective ecological monitoring are dedicated leadership and institutional commitment; strong partnerships among scientists, resource managers, and policy-makers; careful selection of core variables to measure; frequent use of the collected data; plans for long-term data accessibility; and an adaptive monitoring framework that responds to new technologies and research questions (Lovett et al. 2007; Lindenmayer and Likens 2009; Lindenmayer and Likens 2010). Monitoring projects that lack strong research questions and plans for data analysis may become "snowed by a blizzard of ecological details" from a poorly focused "laundry list" of measurements (Lindenmayer and Likens 2010). The "data-rich but information-poor" scenario in environmental monitoring programs (Ward et al. 1986) has led to monitoring programs being criticized as unscientific (Lovett et al. 2007; Lindenmayer and Likens 2009). While these comments are focused on monitoring for academic and research purposes, long-term ecological datasets often address basic research goals while generating useful data for environmental managers and policymakers (Magurran et al. 2010; Lindenmayer and Likens 2010). The same guidelines for effective monitoring apply to urban forests, because long-term monitoring can produce data for both researchers and practitioners.

Survey participants encountered challenges with urban forest monitoring that were previously raised by Baker (1993): consistency in field crew training, accurately recording tree location, and managing data. Often, existing inventory software did not meet participants' needs for long-term data collection and longitudinal data storage. Researchers can significantly improve the quality and consistency of monitoring data across cities by developing standardized protocols, offering technology solutions, and being responsive to practitioner needs and organizational capacities. Standardized monitoring protocols can extend from existing urban forest data standards and inventory methods (Miller 1996; McPherson et al. 1999; Nowak and Crane 2000; Brack 2006; Keller and Konijnendijk 2012), with special attention to issues that are unique to long-term data collection, such as managing longitudinal datasets and accurately recording tree location and DBH growth. Technology solutions for monitoring could include mobile interfaces for data collection and remote sensing to reduce the need for costly ground-based approaches. In offering suggestions for standardized protocols, survey respondents urged researchers to "keep it simple," rather than "complicated and academic," to enable more organizations to participate. Researchers must remain cognizant of the fact that many local organizations engaged in monitoring have a small number of urban forestry staff (one- half with six or fewer), and that most local organizations do not have staff dedicated to database management. Developing, implementing, and analyzing long-term monitoring projects are significant challenges for organizations with few staff and limited resources. By providing standards for long-term data collection and analysis, researchers can enhance the institutional capacity of these organizations to generate rigorous data that addresses their management needs. Standardization would also promote the sharing of information among practitioners. While survey participants recognized many values in sharing monitoring approaches and results, few consulted with external colleagues in developing their methods, and only about half currently share their results and methods with other organizations.

Linking planting grants to monitoring and maintenance funds would be one step forward in addressing the hurdle of resource limitations faced by many local monitoring programs. One-quarter of the programs surveyed were required to monitor due to grant obligations. Urban forestry initiatives should tout exemplary records of tree survival and health, rather than sheer numbers of trees planted. With increased interest in urban tree monitoring from funders, more local organizations may begin monitoring, or may formalize their existing programs. Additionally, regulatory-based programs, such as California's cap and trade offset program (California Air Resources Board 2011), allow for urban tree planting as a mitigation measure because of projected ecosystem services (McHale et al. 2007; Poudyal et al. 2011), and are including reporting requirements for tree survival and growth. Reliable funding sources have also been a concern in long-term environmental and ecological monitoring (Caughlan and Oakley 2001; Lovett et al. 2007), and dedicated funding from national agencies has been important for long-term ecological research in the United States (e.g., LTER and FIA). Finding consistent funding for long-term urban tree monitoring is likely to require new partnerships among federal and state agencies, industries, and non-profits.

Reliance on volunteers for field data collection was one strategy employed by participants to keep costs down, particularly among non-profit organizations. Volunteer-based data collection and citizen science in urban forestry can promote environmental awareness and create a more informed constituency (Bloniarz and Ryan 1996; Cooper et al. 2007; Abd-Elrahman et al. 2010). Citizen science is also employed in long-term ecological monitoring in other systems (Silvertown 2009; Dickinson et al. 2010; Magurran et al. 2010; Dickinson et al. 2012), such as the Audubon Society's Christmas Bird Count. While data collected by volunteers has the potential for error and bias, the extent of this error is poorly understood (Dickinson et al. 2010). Errors can be minimized with data validation procedures whereby scientists follow up on data entries flagged as potential problems (Bonter and Cooper 2012; Gardiner et al. 2012). Bloniarz and Ryan (1996) found that with adequate training, volunteer-based urban tree inventories can produce mostly accurate data at lower cost than professional arborists. The survey participants also noted that effective volunteer and intern training is essential to producing high-quality data.

Collaboration between researchers and practitioners will be essential to develop effective monitoring standards and implement long-term data collection. Dialogue between researchers, managers, and arborists has been central to urban forestry for many decades, recognizing the strengths that each 
party brings to collaborations, as well as the difficulties in two-way communication (Shigo 1976; Dwyer 1987). Survey participants requested that researchers have an inclusive process to develop standards, and create flexible protocols adaptable to different organizations' needs. Collaborative, community-based, and participatory approaches are increasingly common in other disciplines, such as city planning (Forester 1999; Rotmans and Van Asselt 2000), natural resource management (Fortmann 2008; Wilmsen 2008), and public health (O'Fallon and Dearry 2002; Minkler and Wallerstein 2008). Following from the principles of community-based participatory research (O'Fallon and Dearry 2002), local urban forestry organizations should be involved in setting goals, developing methods, collecting data, and disseminating results. For example, Wolf and Kruger (2010) used structured discussions among urban forest managers, professionals, and researchers in the U.S. Pacific Northwest to identify and prioritize research topics. Urban forestry practitioners can contribute their professional expertise and insights into local conditions, thereby enhancing the quality of the research. Continued dialogue between researchers and practitioners will be necessary to ensure that future urban forest monitoring projects are both scientifically rigorous and useful for local management concerns.

\section{CONCLUSION}

To the best knowledge of the study authors, this is the first comprehensive survey of local urban tree monitoring programs in the United States. As such, the study provides information to establish a baseline for current practices in urban forest monitoring. It was found that monitoring programs are chiefly implemented by non-profits and municipal agencies to measure program success, inform on management practices, and provide educational experiences for volunteers and communities. Insufficient staff time and funds for monitoring are primary limitations. Representatives from monitoring programs expressed eagerness to share monitoring strategies and lessons learned. Participants stressed that decisions about what data to collect should closely align with monitoring goals. The development and adoption of standardized monitoring protocols would assist these organizations by diverting scarce resources from protocol development to crew training and field data collection.

The results and conclusions may be biased due to the limited sample size; there may be other urban tree monitoring programs in the United States that were unintentionally omitted. Nevertheless, by including 32 organizations with a range of characteristics and monitoring methods, sufficient information was gathered to assess the goals, challenges, methods, and uses of practitionerdriven monitoring. The observations gleaned from this survey can inform the next generation of urban tree monitoring, with researchers and practitioners collaborating for long-term data collection.

Acknowledgments. We are grateful to all participants for their time and effort completing the survey, and for sharing their insights into urban forest monitoring. We thank the following individuals for providing references to local urban forestry organizations: J. Dwyer, D. Hartel, A. Siewart, and P. Smith. We also thank L. Fortmann, A. Benner, and J. Caditz for critiquing the draft questionnaire, J. McBride, J. Battles, L. Mozingo, D. Nowak, L. Westphal, and three anonymous reviewers for their comments on the manuscript. We thank F. Champenois and J. Tang for assistance with data analysis and compilation. We appreciate the input of attendees at the Urban Tree Growth \& Longevity Symposium in Lisle, Illinois, U.S. (September 2011); the roundtable discussion at the conference directed us to conduct this survey. Attendees at urban tree monitoring symposium at the International Society of Arboriculture's Annual Conference \& Trade Show in Portland, Oregon, U.S. (August 2012) also provided valuable feedback on the preliminary results.

\section{LITERATURE CITED}

Abd-Elrahman, A.H., M.E. Thornhill, M.G. Andreu, and F. Escobedo. 2010. A community-based urban forest inventory using online mapping services and consumer-grade digital images. International Journal of Applied Earth Observation and Geoinformation 12:249-260.

Babbie, E.R. 2007. The basics of social research. Wadsworth: 576 pp.

Baker, F.A. 1993. Monitoring the urban forest: Case studies and evaluations. Environmental Monitoring and Assessment 26:153-163.

Bloniarz, D.V., and H.D.P. Ryan. 1996. The use of volunteer initiatives in conducting urban forest resource inventories. Journal of Arboriculture 22:75-82.

Bonter, D.N., and C.B. Cooper. 2012. Data validation in citizen science: A case study from Project FeederWatch. Frontiers in Ecology and the Environment 10:305-307.

Boyce, S. 2010. It takes a stewardship village: Effect of volunteer tree stewardship on urban tree mortality rates. Cities and the Environment 3: article $3.8 \mathrm{pp}$.

Brack, C.L. 2006. Updating urban forest inventories: An example of the DISMUT model. Urban Forestry \& Urban Greening 5:189-194.

California Air Resources Board. 2011. Compliance Offset Protocol: Urban Forest Projects. Sacramento, CA, California Environmental Protection Agency, Air Resources Board. 113 pp.

Caughlan, L., and K.L. Oakley. 2001. Cost considerations for long-term ecological monitoring. Ecological Indicators 1:123-134.

Clark, J.R., N.P. Matheny, G. Cross, and V. Wake. 1997. A model of urban forest sustainability. Journal of Arboriculture 23:17-30.

Cooper, C.B., J. Dickinson, T. Phillips, and R. Bonney. 2007. Citizen science as a tool for conservation in residential ecosystems. Ecology and Society 12:11.

Cumming, A.B., D.B. Twardus, and D.J. Nowak. 2008. Urban forest health monitoring: Large-scale assessments in the United States. Arboriculture \& Urban Forestry 34:341-346.

Dickinson, J.L., B. Zuckerberg, and D.N. Bonter. 2010. Citizen science as an ecological research tool: Challenges and benefits. Annual Review of Ecology, Evolution, and Systematics 41:149-172.

Dickinson, J.L., J. Shirk, D. Bonter, R. Bonney, R.L. Crain, J. Martin, T. Phillips, and K. Purcell. 2012. The current state of citizen science as a tool for ecological research and public engagement. Frontiers in Ecology and the Environment 10:291-297.

Dillman, D.A. 1999. Mail and internet surveys: The tailored design method, 2nd edition. Wiley \& Sons, New York, New York, U.S. 480 pp.

Dwyer, J.F. 1987. How to make research and researchers work more effectively for you. Journal of Arboriculture 13:267-273.

Dwyer, J.F., D.J. Nowak, and G.W. Watson. 2002. Future directions for urban forestry research in the United States. Journal of Arboriculture 28:231-236.

Forester, J. 1999. The deliberative practitioner: Encouraging participatory planning process. MIT Press. $321 \mathrm{pp}$.

Fortmann, L. (Ed.). 2008. Participatory research in conservation and rural livelihoods: Doing science together. Wiley-Blackwell, New York, New York, U.S. 316 pp. 
Gardiner, M.M., L.L. Allee, P.M.J. Brown, J.E. Losey, H.E. Roy, and R.R. Smyth. 2012. Lessons from lady beetles: Accuracy of monitoring data from US and UK citizen-science programs. Frontiers in Ecology \& the Environment 10:471-476.

Keller, J., and C.C. Konijnendijk. 2012. A Comparative Analysis of Municipal Urban Tree Inventories of Selected Cities in North America and Europe. Arboriculture \& Urban Forestry 38:24-30.

Leibowitz, R. 2012. Urban tree growth and longevity: An international meeting and research symposium white paper. Arboriculture and Urban Forestry 38:237-241.

Lindenmayer, D.B., and G.E. Likens. 2009. Adaptive monitoring: A new paradigm for long-term research and monitoring. Trends in Ecology \& Evolution 24:482-486.

Lindenmayer, D.B., and G.E. Likens. 2010. The science and application of ecological monitoring. Biological Conservation 143:1317-1328.

Lovett, G.M., D.A. Burns, C.T. Driscoll, J.J. Jenkins, M.J. Mitchell, L. Rustad, J.B. Shanley, G.E. Likens, and R. Haeuber. 2007. Who needs environmental monitoring? Frontiers in Ecology and the Environment 5:253-260.

Lu, J.W.T., E.S. Svendsen, L.K. Campbell, J. Greenfeld, J. Branden, K.L. King, and N. Flaxa-Raymond. 2010. Biological, social, and urban design factors affecting young street tree mortality in New York City. Cities and the Environment 3: article 5. 15 pp.

Magurran, A.E., S.R. Baillie, S.T. Buckland, J. McP. Dick, D.A. Elston, E.M. Scott, R.I. Smith, P.J. Somerfield, and A.D. Watt. 2010. Longterm datasets in biodiversity research and monitoring: Assessing change in ecological communities through time. Trends in Ecology and Evolution 25:574-582.

McHale, M.R., E.G. McPherson, and I.C. Burke. 2007. The potential of urban tree plantings to be cost effective in carbon credit markets. Urban Forestry \& Urban Greening 6:49-60.

McPherson, E.G. 1993. Monitoring urban forest health. Environmental Monitoring and Assessment 26:165-174.

McPherson, E.G., J.R. Simpson, P.J. Peper, and Q. Xiao. 1999. Benefitcost analysis of Modesto's municipal urban forest. Journal of Arboriculture 25:235-248.

McPherson, E.G., and J.R. Simpson. 2002. A comparison of municipal forest benefits and costs in Modesto and Santa Monica, California, USA. Urban Forestry \& Urban Greening 1:61-64.

McPherson, G., J.R. Simpson, P.J. Peper, S.E. Maco, and Q. Xiao. 2005. Municipal forest benefits and costs in five US cities. Journal of Forestry (Dec.). pp. 411-416.

Miller, R.W. 1996. Urban forestry: Planning and managing urban green spaces, 2nd edition. Prentice Hall, Hoboken, New Jersey, U.S. 480 pp.

Minkler, M., and N. Wallerstein (Eds.). 2008. Community-based participatory research for health: From process to outcomes, 2nd edition. Jossey-Bass. 544 pp.

Nowak, D.J., and D.E. Crane. 2000. The urban forest effects (UFORE) model: quantifying urban forest structure and functions. pp. 714720. In: M. Hansen and T. Burk (Eds.). Integrated Tools for Natural Resources Inventories in the 21 st Century. Proc. of the IUFRO Conference. USDA Forest Service, GTR NC-212, St. Paul, MN. 744 pp.

Nowak, D.J., M.K. Kuroda, and D.E. Crane. 2004. Tree mortality rates and tree population projections in Baltimore, Maryland, USA. Journal of Urban Forestry \& Urban Greening 2:139-147.

Nowak, D.J., D.E. Crane, J.C. Stevens, R.E. Hoehn, J.T. Walton, and J. Bond. 2008. A ground-based method of assessing urban forest structure and ecosystem services. Arboriculture \& Urban Forestry 34:347-358.
Nowak, D.J., R.E. Hoehn, A.R. Bodine, E.J. Greenfield, and J. O'Neil-Dunne. 2013. Urban forest structure, ecosystem services and change in Syracuse, NY. Urban Ecosystems (in press) DOI: 10.1007/s11252-013-0326-Z.

O'Fallon, L.R., and A. Dearry. 2002. Community-based participatory research as a tool to advance environmental health sciences. Environmental Health Perspectives 110:155-159.

Poudyal, N.C., J.P. Siry, and J.M. Bowker. 2011. Quality of urban forest carbon credits. Urban Forestry \& Urban Greening 10:223-230.

Roman, L.A. 2013. Urban Tree Mortality, Ph.D. thesis, University of California, Berkeley, Berkeley, California, U.S. 109 pp.

Rotmans, J., and M.B.A. Van Asselt. 2000. Towards an integrated approach for sustainable city planning. Journal of Multi-criteria Decision Analysis 9:110-124.

Rysin, L.P., L.I. Savel'eva, and S.L. Rysin. 2004. Forest monitoring in urbanized areas. Russian Journal of Ecology 35: 209-213.

Shigo, A.L. 1976. Communication of knowledge and needs between research and arboriculturalist. Journal of Arboriculture vol: 206-208.

Silvertown, J. 2009. A new dawn for citizen science. Trends in Ecology and Evolution 24:467-471.

Ward, R.C., J.C. Loftis, and G.B. McBride. 1986. The "data-rich but information-poor" syndrome in water quality monitoring. Environmental Management 10:291-297.

Weinstein, G. 1983. The Central Park tree inventory: A management model. Journal of Arboriculture 9:259-262.

Wilmsen, C. (Ed.). 2008. Partnerships for empowerment: Participatory research for community-based natural resource management. Routledge, London, UK. 320 pp.

Wolf, K.L., and L.E. Kruger. 2010. Urban forestry research needs: A participatory assessment process. Journal of Forestry Jan/Feb:39-44.

Lara A. Roman (corresponding author)

USDA Forest Service

Northern Research Station

Philadelphia Field Station

100 N. 20th St., Suite 205

Philadelphia, Pennsylvania 19103, U.S.

lroman@fs.fed.us

\section{E. Gregory McPherson}

USDA Forest Service

Pacific Southwest Research Station

Urban Ecosystems and Social Dynamics Program

1731 Research Park Dr.

Davis, California 95618, U.S.

Bryant C. Scharenbroch

Research Department

The Morton Arboretum

4100 Illinois Route 53

Lisle, Illinois 60532-1293, U.S.

\section{Julia Bartens}

Department of Forest Resources and Environmental Conservation Virginia Tech

Blacksburg, Virginia 24061, U.S. 
Zussamenfassung. Die Daten aus der Überwachung urbaner Forste sind notwendig für die Bewertung des Einflusses von Baumpflanzaktionen und Pflegeprogrammen. Lokale Anwender haben Überwachungsprojekte, welche bislang in der Literatur zur Urbanen Forstwirtschaft nicht gut dokumentiert wurden. Um mehr über die Anwender-gesteuerten Überwachungsprojekte zu lernen, befragten die Forscher 32 lokale urbane Forstorganisationen in den USA über Zielsetzungen, Herausforderungen, Methoden und Gebrauch ihrer Überwachungsprogramme, indem sie per email einen Fragebogen verschickten. Nicht gewinnorientierte Organisationen, kommunale Dienststellen, staatliche Dienststellen und Versorgungsunternehmen nahmen daran teil. Eine Hälfte der Organisationen hatte sechs oder weniger Mitarbeiter. Allgemeine Ziele der Überwachung schlossen eine Bewertung des Erfolgs von Pflanzungen und Pflege ein, wobei eine Initiative zur Baumpflege ergriffen wurde und zur Einbeziehung der Kommunen. Die meisten allgemein aufgezeichneten Daten betrafen Baumarten, Zustandsbewertungen, Sterberaten und Durchmesser in Brusthöhe. Die Herausforderung bestanden in begrenzten Mitarbeitern und Mitteln, Schwierigkeiten mit der Datenverwaltung und Technologie, sowie praxisorientierte Mitarbeiterschulung. Die Programme nutzten die Überwachungsergebnisse, um Baumpflanzungen und Pflegemaßnahmen anzuweisen, liefern Feedback an verantwortliche Personen in der Pflege und verwalten Baumrisiken. Die Anwender hoben die Bedeutung der vorausgehenden Planung hervor: eine sorgfältige Abwägung, welche Daten zu sammeln sind, klare ziele zu setzen, eine anwenderfreundliche Datensammlung zu entwickeln, sowie eine Planung für benötigte Mittel der Umsetzung einschließlich Mitarbeiterzeit. Um die Qualität und Konsistenz der erhobenen Daten in den Städten zu verbessern, können die Forscher standardisierte Protokolle entwickeln und auf die Bedürfnisse der Anwender und organisatorischen Kapazitäten eingehen.
Resumen. Los datos del monitoreo de los bosques urbanos son esenciales para evaluar el impacto de las campañas de plantación de árboles y programas de gestión. Los practicantes locales han dado seguimiento de los proyectos que no han sido bien documentados en la literatura forestal urbana. Para obtener más información sobre los esfuerzos de monitoreo, los investigadores encuestaron a 32 organizaciones forestales urbanas locales en los Estados Unidos acerca de las metas, retos, métodos y usos de los programas de control, mediante un cuestionario enviado por correo electrónico. Participaron las organizaciones no lucrativas, agencias municipales, agencias estatales y servicios públicos. La mitad de las organizaciones tenía seis o menos personal de dasonomía urbana. Los objetivos comunes para el monitoreo incluyeron la evaluación del éxito de la plantación y manejo de árboles, tomando un enfoque proactivo hacia el cuidado de los árboles con la participación de las comunidades. Los datos registrados más comunes fueron las especies, calificación de condición, el estado de la mortalidad y el diámetro a la altura del pecho. Los desafíos incluyen limitaciones de personal y la financiación, las dificultades con la gestión y la tecnología de información y formación del equipo de campo. Los programas utilizan los resultados del monitoreo para informar de la plantación de árboles y las prácticas de mantenimiento, proporcionar información a las personas responsables del cuidado del árbol y gestionar el riesgo del árbol. Los participantes hicieron hincapié en la importancia de planificar: considerando cuidadosamente los datos a colectar, estableciendo objetivos claros, desarrollando bases de datos adecuadas y planeando los fondos y el tiempo del personal. Para mejorar la calidad y la consistencia del monitoreo de datos a través de las ciudades, los investigadores pueden desarrollar protocolos estandarizados y ser sensibles a las necesidades y capacidades organizativas de los practicantes. 